\title{
Domestic Violence Shelters: Exploring Secondary Traumatic Stress of Female
}

\section{Counsellors}

\author{
Nancy L Beckerman* and Hanni B Flaherty \\ Wurzweiler School of Social Work, Yeshiva University, New York, USA
}

*Corresponding author: Beckerman NL, Professor, Wurzweiler School of Social Work, Yeshiva University, New York, USA, Tel: (212)960-0839; E-mail: nlbeckerman@gmail.com

Received: October 19, 2019; Accepted: October 26, 2019; Published: November 04, 2019

\section{Introduction}

Counsellors in domestic violence (DV) shelters have long reported extraordinary stressors, fear for their clients' safety, and fear for their own safety [1-7]. DV counsellors in shelter settings are often tasked with pervasive trauma work after a violent episode in their clients' lives. The intake for a new DV resident often includes the debriefing of life-threatening violence after years of domestic violence. However, little is known about the effects of secondary trauma on the counsellors in shelter work [4]. With intense and chronic levels of trauma exposure, social work does know that this is a particularly vulnerable cohort of counsellors who may themselves; suffer from compassion fatigue, burnout and secondary trauma [5].

Because it is very difficult to recruit such a focused and delineated group of (all women, all women of color who provide counseling in DV shelters), this is groundbreaking, albeit limited, new lacuna of knowledge solely focused on an all women of color in dv shelters as a sample. While STS has been examined in a variety of trauma settings, this is the first in a group of urban DV shelters compromised entirely of women of color as counsellors.

There is no existing literature that specifically explores the racial and ethnic composition of domestic violence shelter counsellors, so this study begins to address that gap as all participant counsellors are not only women, but women of color. Therefore, the likelihood of experiencing identification, whether that is referred to as parallel process or induced counter transference with the trauma survives is heightened.

\section{Literature Review}

\subsection{Domestic violence shelters}

Domestic violence accounts for over $20 \%$ of all violent crime in the US (CDC) More than 1 in 3 women will be victims of intimate partner violence in their lifetimes Women between the ages of 18 and 24 are the most likely to experience domestic violence and women are most likely to be their primary caretakers in formal and informal settings. Emergency shelter and

Citation: Beckerman NL, Flaherty HB. Domestic Violence Shelters: Exploring Secondary Traumatic Stress of Female Counsellors. 2019;2(2):116. 
www.yumedtext.com | November-2019

transitional housing for those fleeing this violence continues to be a most urgent unmet need for domestic violence survivors. Survivors have reported that if a domestic violence shelter did not exist, the consequences for them would be dire: homelessness, serious losses including loss of their children, actions taken in desperation, or continued abuse or death [8].

93\% of mothers experienced at least one trauma and $81 \%$ experienced multiple traumatic events. Seventy-nine percent experienced trauma in childhood, $82 \%$ in adulthood, and $91 \%$ in both adulthood and childhood. Violent victimization was the most common traumatic experience; $70 \%$ reported being physically assaulted by a family member or someone they knew and approximately half had been sexually assaulted [9]. Thirty-eight percent of all domestic violence victims become homeless at some point in their lives.

Results of a nationwide study about domestic violence reports and availability of DV shelters, showed substantial unmet demand for services (10\% of requests being filled in a timely manner) because of resource constraints, economically disadvantaged, and minority communities. This has resulted in high volume caseloads and pressure to transition survivors quickly to post-shelter housing [10].

\subsection{Role and function of domestic violence counsellors}

Who are DV counsellors? Women constitute $81.6 \%$ of social workers, $69.9 \%$ of counsellors, and $82.4 \%$ of social and human service assistants; comprising the overwhelming majority of DV counsellors. Because of the taboo and likelihood that domestic violence was wielded by the men in their lives, DV counsellors are almost entirely women [11]. A smaller subset of same- sex violence does occur between women, but the identity of perpetrator was not explored in this survey.

It is the domestic violence shelter counsellors' role to provide safety planning immediately after the last traumatic violent event, psychoeducation, information and advocacy about domestic violence and help the survivor to establish some safer equilibrium (physically and emotionally). Through this all, it is the counsellors who are also the primary source of emotional support and strength as the survivor moves through the additional trauma of shelter living and a safer return to the community [12]. Often the shelter itself is experienced as oppressive to both resident and counsellor with numerous rules about entering and exiting the shelter and the neighbourhood [12]. The most extensive study of domestic violence shelters residents ( $\mathrm{n}=565)$ over eight states, reported that domestic violence survivors entered residential shelters with diverse needs, but foremost is usually safety $[12,13]$. The DV counsellors who provide trauma counselling to domestic violence survivors are exposed to ongoing and pervasive stories of terror, danger, physical and emotional violence. The nature of this work includes both acute stages of trauma, complex trauma and post-traumatic stress disorder with little or no access to the outcome once residents leave the shelter $[5,14,4]$. There is often hyper vigilance, police and legal reports and court appearances and the worker and the survivor may share in a parallel process of feeling overwhelmed and fearful [4].

\subsection{Secondary traumatic stress among domestic violence counsellors}

The term Vicarious Traumatisation (VT) was coined by Pearlman [15] to describe the profound shift in world view that occurs in helping professionals when they work with individuals who have experienced trauma: helpers notice that their fundamental beliefs about the world are altered and possibly damaged by being repeatedly exposed to traumatic material. A domestic violence shelter worker may stop being able to believe that any relationship can be healthy. A child abuse 
www.yumedtext.com | November-2019

investigator may lose trust in anyone who approaches their child. Again, examples of this abound and vary based on the type of work that we do.

Secondary Traumatic Stress (STS) is a concept that was developed by trauma specialists Beth Stamm, Charles Figley and others in the early 1990s as they sought to understand why service providers seemed to be exhibiting symptoms similar to Post Traumatic Stress Disorder (PTSD) without having necessarily been exposed to direct trauma themselves [16].

Bell, Kulkarni, \& Dalton and Figley, [17,18] defined secondary traumatic stress (STS) as the experiencing of emotional duress in persons who have had close contact with a trauma survivor, which may include family members as well as therapists. STS symptoms include the three broad planes of PTSD: 1) re-experiencing the traumatic event shared, 2) avoidance, and/or numbing in response to reminders of this event, 3) and persistent arousal and hypervigilance [6,19,18]. More recently, Baird et al., [3] defined STS as a set of psychological symptoms that mimic post-traumatic stress disorder but is acquired through exposure to persons suffering the effects of trauma [3,20,21].

In STS, the counsellor begins to experience physical and psychological trauma after exposure to direct contact with clients who have shared their traumatic emotional experiences [19]. This worldview and emotional state often affect the direct work with clients as well as the intrapsychic world of the direct practitioner [6,20,22-24].

Research has identified several of the potential pre-morbid and co-morbid psychological factors, that place a mental health counsellor at a higher risk for developing and suffering from the various symptoms of a secondary traumatic stress (STS) $[2,18,22,23,25]$. The more history a counsellor has with their own personal trauma, the more likely that exposure to traumatized clients will develop into STS [13,19,26-28]. In fact, counsellors having a personal history of sexual assault show more symptoms related to psychological trauma than do non-assaulted personnel [19,29,30-33]. Another intervening variable that has a possible correlation to secondary traumatisation is the amount of experience the provider has; the less experience, the more likely the STS $[20,26,34,35]$.

A study from trauma therapists in Poland $(n=80)$, explored the personality traits that might predispose a trauma counsellor to STS and found that emotional reactivity was positively associated with the level of STS symptoms [36]. Schauben \& Frazier [37] determined that the higher the domestic violence workload, the more likely the counsellor will experience STS.

Way, VanDeusen, Martin, Brooks, \& Jandle [7], compared vicarious trauma in a random sample of clinicians who treat domestic violence survivors $(n=95)$ and those who treat offenders $(n=252)$. Findings demonstrated that both groups of trauma counsellors experienced high levels of avoidance and intrusive thoughts [7]. Dworkin, Sorell, \& Allen [34] studied sexual assault workers $(n=164)$ and found that younger age and greater severity of sexual assault history were statistically significant individual-level predictors of increased STS.

When working in a DV shelter, counsellors must be alert to the fact that while the actual physical abuse may no longer be occurring, the assault survivor is still psychologically reverberating, in the form of fear from stalking and the fear of retaliation for leaving the relationship, and this may seep into the provider's psyche as well $[23,30,38,39]$. 
www.yumedtext.com | November-2019

\subsection{Support for domestic violence counsellors}

For frontline DV counsellors, there is often the reality of the immediate crisis, the large caseload and the developing of a safety and discharge plan and clinical supervision can seem like a luxury to both the counsellor and the supervisor [5]. The wish to go deeper and continue to hone clinical skills in the face of so many residents who are in a multipronged crisis has been a difficult wish to fulfil in most shelters [31,11].

Many shelters are too crisis-ridden with urgent decisions to be made to keep women and their children safe and off the street and supervision in this area does not always include comprehensive theoretical frameworks and practice principles [4,5] or the potential perils of working solely with domestic violence survivors at the height of their crisis. Hensley, [40] underscores the unique importance of psycho education, training, and supportive supervision that is critical to substantive and responsive clinical social work supervision [41]. In these ways, DV counsellors can experience feelings of oppression in the sheer volume of cases as well as the nature of the work- and in this way, some may feel unsupported and taken advantage of [4]. It is not lost that the DV survivors and the counsellors in shelters are women in most, if not all, settings [5].

Clinical supervision that is both informative and supportive shores up higher levels of clinical work with DV clients and protects somewhat from developing acute and chronic levels of psychic distress from the traumatic nature of this counselling work [24]. Trauma providers have often lamented that they feel helpless in the face of ongoing acute trauma; that they wish they could do more [42]. Others have cited feeling angry because even though they had the time to devote to their clients, what they could do for them was just not enough. Physical and mental exhaustion were reported as the days stretched to months [42].

\section{Methods}

With DV counsellors at risk for STS, they are more vulnerable to the negative impact on their own mental health and wellbeing, and in turn, at risk for providing less than professionally objective assessment and care of vulnerable clients. This quantitative study attempts to further identify the range of STS levels experienced by counsellors in this domain. The more social workers understand the impact this work may have on DV counsellors, the more the field can tailor a more responsive model of orientation, mentoring, training, and supervision.

\subsection{Sample}

This survey utilized a convenience sample drawn from four DV shelters. Twenty-three DV counsellors were asked to anonymously complete the Secondary Traumatic Stress Scale to identify the existence and prevalence of secondary traumatisation. Seventeen out of the 23 DV counsellors responded to the STSS for a response rate of 73.91 percent.

The eligibility criteria included: A) A mental health counsellor providing services in a domestic violence shelter (MSW or Mental Health Counselling degree), B) currently or recently having worked as a counsellor in a domestic violence shelter, C) No prior self-reported PTSD prior to shelter work, D) provision to adult shelter residents not children. Counsellors (the great majority with five years or less experience) from four different shelters were recruited. Flyers provided by the researcher in conjunction with respective clinical supervisors were used to recruit participants in three separate domestic violence shelters 
www.yumedtext.com | November-2019

in the Northeastern, U.S. In convenience sampling but Five provided services solely to children and not adults, and therefore they were not selected into study.

The convenience sampling resulted in 17 counsellors over a period of a year, who was assured of strict confidentiality with no identifying factors of the shelter or location other than Northeastern, U.S. This is a particularly important point, because confidentiality of where a shelter may be located and the name of a particular shelter are absolutely never to be shared as it may put the residents, even the counsellors in direct danger.

\subsection{Measurement}

There are numerous existing instruments that measure post-traumatic stress disorder in individuals who are directly exposed to trauma. Secondary traumatisation can develop in individuals from exposure to or work with individuals suffering from the post-traumatic stress disorder. Symptoms of secondary traumatisation, such as intrusion, avoidance, and arousal are comparable to those seen in post-traumatic stress disorder. Due to the similarities in symptoms and predominantly anecdotal evidence of secondary traumatisation, researchers have utilized scales that are valid and reliable for measuring symptoms felt by trauma directly to measure secondary traumatisation. Researchers developed the Secondary Traumatic Stress Scale (STSS) [43]. The STSS was selected for this study because it identifies trauma symptoms in social workers and other helping professionals exposed to secondary trauma by utilizing wording that is specifically directed towards professionals working with trauma clients [43].

The STSS is a self-report scale with a response format of 1 to 5 (never to very often). The scale is scored by summing the items of the full STSS as well as individually summing the items allocated to each of the three subscales, Intrusion (items 2 , 3, 6, 10, 13), Avoidance (items 1, 5, 7, 9, 12, 14, 17), and Arousal (items 4, 8, 11, 15, 16) [42]. The STSS was initially developed as a 65 items instrument but was reduced to a 17 item self-report Likert scale after researchers utilized a structural equation modelling method to generate one item to represent each symptom outlined by the DSM-IV for PTSD. An example is found below in TABLE 1:

TABLE 1. Examples of items in the Bride (2004) STSS Scale.

\begin{tabular}{|c|c|c|}
\hline & (1) Never, (2) Rarely, (3) Occasionally, (4) Often, (5) Very Often & \\
\hline 1 & I felt emotionally numb & 12345 \\
\hline 2 & My heart started pounding when I thought about my work with clients & 12345 \\
\hline 3 & It seemed as if I was reliving the trauma(s) experienced by my \\
client(s) & 12345 \\
\hline 4 & I had trouble sleeping & 12345 \\
\hline 5 & I felt discouraged about the future & 12345 \\
\hline
\end{tabular}

The full scale $\alpha=.93, M=29.49, S D=10.76)$ and the subscales, intrusion (.80), avoidance (.89), and arousal (.85) are high in reliability when measuring internal consistency [43]. 
www.yumedtext.com | November-2019

\subsection{Data analysis}

Stata statistical software was utilized for descriptive statistical methods to generate frequency distributions and percentages for the study population. One-way ANOVA test was utilized to test for significance. Pearson's correlation was used to test the strength of the association between dependent and independent variables. The demographic variables of A) age, B) degree, C) race, D) length of time at DV shelter, and E) caseload were not statistically significant with STSS scores and showed no difference internally within any of these variables.

\subsection{Findings}

TABLE 2 displays the socio-demographic information from the data collected, such as counsellors' gender, age, race, caseload, degree, and amount of time spent working with trauma clients in a DV shelter. The sample entirely identified as female $(n=17,100 \%)$. The majority of the sample $(64.71 \%)$ ranged in age from 31-50 years old ( $n=11)$, with only one participant above 51 years old (5.88\%), and 5 participants (29.41\%) under 30 years old. Over half of the sample identified as Black $(70.59 \%, n=12)$ and the remaining $29.41 \%(n=5)$ identified as Hispanic. The entire cadre of DV counsellors were women of color, and this is particularly noteworthy when we look at the intersection of violence against women, violence against women of color and the potential impact on DV counsellors who mirror gender and race of their clients. The sample predominately consisted of counsellors with MSW degrees $(70.59 \%, n=12)$, followed by 4 BSW degrees (23.53\%), and 1 "other" degree (5.88\%). Just under half (47.06\%) of the participants have been working in their respective DV shelters for 1 to 3 years $(n=8)$, three participants $(17.65 \%)$ have been working for less than 1 year, 4 participants $(23.53 \%)$ have been working for more than 3 years, and only 2 participants $(11.76 \%$ ) have been working in their shelter for more than 5 years. Lastly, the participants' client caseloads vary from 20-30 $(n=1,5.88 \%), 30-40(n-8,47.06 \%)$, and caseloads of over 40 clients $(\mathrm{n}=8,47.06 \%)$.

TABLE 2. Sample Characteristics $(N=17)$.

\begin{tabular}{|c|c|c|}
\hline & $\mathbf{N}$ & $\%$ \\
\hline Gender & \multirow[b]{2}{*}{17} & \multirow[b]{2}{*}{100} \\
\hline Female & & \\
\hline \multicolumn{3}{|l|}{ Age } \\
\hline Under 30 & 5 & 29.41 \\
\hline $31-50$ & 11 & 64.71 \\
\hline $51-65$ & 1 & 5.88 \\
\hline \multicolumn{3}{|l|}{ Race } \\
\hline Hispanic & 5 & 29.41 \\
\hline Black & 12 & 70.59 \\
\hline
\end{tabular}


www.yumedtext.com | November-2019

\begin{tabular}{|c|c|c|}
\hline Degree & \multirow[b]{2}{*}{4} & \multirow[b]{2}{*}{23.53} \\
\hline BSW & & \\
\hline MSW & 12 & 70.59 \\
\hline Other degree & 1 & 5.88 \\
\hline \multicolumn{3}{|c|}{ Length of time working at a DV shelter } \\
\hline Under 1 year & 3 & 17.65 \\
\hline $1-3$ years & 8 & 47.06 \\
\hline More than 3 years & 4 & 23.53 \\
\hline More than 5 years & 2 & 11.76 \\
\hline \multicolumn{3}{|l|}{ Caseload } \\
\hline $20-30$ & 1 & 5.88 \\
\hline $30-40$ & 8 & 47.06 \\
\hline Over 40 & 8 & 47.06 \\
\hline
\end{tabular}

The major finding of this study emerged when 9 participants (52.9411\%) scored a 3 or higher in each category. According to Bride et al, [43] for a participant to demonstrate secondary traumatic stress disorder, they would need to have at least 1 intrusion item above a 3 score, 3 avoidance items above a 3 score, and 2 arousal items above a 3 score. This is extraordinarily high a) they didn't identify as having PTSD prior to survey and b) general population rate of STSS. These rates are higher than in the general US population, in which the current prevalence is 3.5\% and the lifetime prevalence is $6.8 \%$ [44]. In Bride's 2007 study of 282 master's-level social workers, results found that " 70.2 percent experienced at least one symptom [of secondary trauma] in the previous week, 55 percent met the criteria for at least one of the core symptom clusters, and 15.2 percent met the core criteria for a diagnosis of PTSD" [45]. this study's findings suggest that $15.2 \%$ of social workers experience secondary trauma due to their client's trauma.

Further analysis of the secondary traumatic stress symptoms shows that the majority of the participants reported symptoms of avoidance $(41.6 \%)$ over intrusion $(31.5 \%)$ and arousal $(28 \%)$. The highest scoring question refers to wanting to avoid working with clients followed by the question referring to thinking about client when they did not intent to and third, avoiding people, places and things that remind them of their work with clients. This is consistent with prior research in which domestic violence workers in shelters found themselves trying to avoid thinking about their clients, avoiding areas near the shelter, avoiding talking about work with family and friends [4]. The intrusion of unwanted thoughts about the traumas they have been exposed to occurs in a third of the workers, which is also consistent with other research on this population $[4,25]$. This analysis shows that not only are large number of clinicians who provide services related to DV experiencing secondary traumatic stress but are responding to these stressors with avoidance patterns. 
www.yumedtext.com | November-2019

\section{Discussion}

This study demonstrates that STS may be higher (52.9\%) than the prevalent norm when working with DV survivors. Furthermore, having PTSD prior to working with DV survivors may not be a precursor for STS. A factor to consider is that the providers are engaging with DV survivors, not in an interdisciplinary hospital setting, but are being treated immediately after the last attack has left them with no other options. Survivors are encountering the providers when the level of DV had become intolerable and thus sharing their trauma narratives immediately after the apex of the crisis. The combination of acuity, the lack of resources, and the immediacy of the crisis combine for this to be particularly impacting for the providers and resulting in heightened incidences of STS. Further exploration and understanding of the effects of secondary trauma on providers is needed to provide support and education around self-care. Providers must be able to guard themselves against the impact of secondary traumatisation as to continue to provide high-quality care to the victims who are their clients.

\section{Implications}

\subsection{Social work education}

It has become increasingly apparent, as shown in this study, that social workers engaged in direct practice within DV shelters are highly likely to be secondarily exposed to traumatic events through their work with their clients. This exposure leads to symptoms of STS among providers. "STS is becoming viewed as an occupational hazard of providing direct services to traumatized populations" [45].

To prevent burnout and reduce symptoms of STS, the discussion around self-care should begin while the providers are students and continue throughout their careers. To safeguard against STS social work, students should be educated around symptoms of STS and the importance of self-care. Currently, self-care is not often part of the core MSW and BSW education.

The importance of self-care should be integrated throughout and within the course material as to reduce STS among providers especially for DV workers as to promote longevity and continuation of this important care.

\subsection{Supervision}

Much has been written about the importance of supervision for all mental health providers [16,41,46-48] and having a supervisor who is not only providing administrative oversight but is providing authentic clinical supervision in the reduction of STS. Reducing STS require that a provider have a positive relationship with a person who serves as his or her supervisor. Clinical supervision that promotes an atmosphere of respect, safety, and trust can help to minimize STS among counsellors specifically in DV shelters. Supervision should focus on counter transference, parallel process, and the vulnerability of DV workers to STS. Supervisors can contribute to the emotional well-being of providers by sharing personal and professional stories, and expressing openness to the feelings and concerns of supervisees, and through the use of self-disclosure to promote an atmosphere where providers are able to take risks, discuss their mistakes, and learn from them [47,49]. There is evidence that proper training and support through supervision can reduce secondary traumatisation and burnout $[24,40,50]$.

\subsection{Policy and program development}

Specific practices and procedures could be implemented within organizations to improve the emotional well-being of providers in domestic violence shelters. Employers, supervisors, and others often encourage providers who have symptoms of 
www.yumedtext.com | November-2019

STS to practice self-care, and organizations can influence the work of caregivers in ways that reduce STS. Institutional support of self-care can have a significant impact on the quality of care provided and the reduction of STS. Orientation and on boarding programs should include self-care and psychoeducation about the potential for developing STS. Furthermore, inservice training, education, and supervision support should consist of screening for STS and emphasis on self-care due to the high rate of STS among DV workers.

The primary limitation of this study and report is the small sample size, reducing the ability generalize the findings to the larger area of domestic violence work, as well as other areas of trauma-informed social work practice. However, it is a snapshot of a representative group (DV workers largely comprised small of women counsellors), and the potential impact DV shelter work may have on those providing direct counselling. This is a convenience sample that represents only those counsellors that were interested in responding to this questionnaire. This may skew the results in that those who were in need of talking about the stress of their work in the shelters were more inclined to participate.

\section{Conclusion}

Although further exploration and understanding of the effects of STS on providers are needed, this study highlighted the importance of guarding providers against the impact of secondary traumatisation. Finding that over $52.9 \%$ of DV shelter workers have experienced STS is an essential finding. Furthermore, this is a valuable study as this is the first to include a group of urban DV shelters compromised entirely of women of color. Shelter work presents emotional and unique challenges to DV counsellors. Policy and program development, clinical supervision and education can increase providers' ability to guard themselves against the impact of secondary traumatisation through self-care resulting in the continued provision of high-quality care to the victims who are their clients.

\section{REFERENCES}

1. Astin, MC. Traumatic therapy: How helping rape victims affects me as a therapist. Women Ther. 1997;20(1):101-9.

2. Baird S, Jenkins S. Vicarious traumatization, secondary traumatic stress, and burnout in sexual assault and domestic violence agency staff. Violence Vict. 2003;18(1):71-86.

3. Baird K, Kracen A. Vicarious traumatization and secondary traumatic stress: A research synthesis. Couns Psychol Q. 2006;19(2):181-8.

4. Beckerman NL, Wozniak DF. Domestic violence counselors and secondary traumatic stress (STS): A brief qualitative report and strategies for support. Soc Work Ment Health. 2018;16(4):470-90.

5. Ben-Porat A. Vicarious post-traumatic growth: Domestic violence therapists versus social service department therapists in Israel. J Fam Violence. 2015;30(7):923-33.

6. Brien, KM. Understanding stress and burnout in shelter workers. Professional Psychology: Res Pract. 1998;29(4): 383-5.

7. Way I, VanDeusen K, Martin G, et al. Vicarious Trauma: A comparison of clinicians who treat survivors of sexual abuse and sexual offenders. J Interpers Violence. 2004;19(1):49-71.

8. Lyon E, Lane S, Menard A. Meeting survivors' needs: A multi-state study of domestic violence shelter experiences. Washington, DC: National Institute of Justice, USA; 2008. 
www.yumedtext.com | November-2019

9. Hayes M, Zonneville M, Bassuk E. The SHIFT Study final report: Service and housing interventions for families in transition. Newton, MA: National Center on Family Homelessness, USA; 2013.

10. Iyengar R, Sabik L. The Dangerous Shortage of Domestic Violence Services. Health Aff. 2009;28(Suppl 1).

11. NASW. Need Therapy? A Good Man Is Hard to Find. New York Times. 2011.

12. Sullivan CM. Domestic Violence Shelter Services: A Review of the Empirical Evidence. Harrisburg: National Resource Center on Domestic Violence, USA; 2016.

13. Illiffe G, Steed L. Exploring the counselor's experience of working with perpetrators and survivors of domestic violence. J Interpers Violence. 2000;15(4):393-412.

14. Ben-Porat A, Itzahky H. The Contribution of Training and Supervision to Perceived Role Competence, Secondary Traumatization, and Burnout Among Domestic Violence Therapists. Clin Superv. 2011;30(2):95-108.

15. Pearlman LA and McCann L. Vicarious traumatization: A framework for understanding the psychological effects of working with victims. J Trauma Stress. 1990;3(1):131-49.

16. Neuman DA, Gamble SJ. Issues in the professional development of psychotherapists: Countertransference and vicarious traumatization in the new trauma therapist. Psychother. 1995;32(6):341-34.

17. Bell H, Kulkarni S, Dalton L. Organizational prevention of vicarious trauma. Fam Soc. 2003;84(4):463-70.

18. Figley CR. Compassion fatigue as secondary traumatic stress disorder: An overview. In: Figley CR, editor. Compassion fatigue: Coping with secondary traumatic stress disorder in those who treat the traumatized. New York: Brunner/Mazel, USA; 1995. 1-20 p.

19. Cunningham M. The impact of trauma work on social work clinicians: Empirical findings. Soc Work. 2003;48(4):451-9.

20. Jenkins S, Mitchell J, Baird S, et al. The counselor's trauma as counseling motivation: Vulnerability or stress inoculation? J Interpers Violence. 2012;26(12): 2392-2412.

21. Sabin-Farrell R, Turpin G. Vicarious traumatization: Implications for the mental health of health workers? Clin Psychol Rev. 2003;23(3):449-80.

22. Clemans SE. Recognizing vicarious traumatization: A single session group model for trauma workers. Social Work with Groups. 2004;27(2/3):55-74.

23. Johnson CNE, Hunter M. Vicarious traumatization in counsellors working in the new South Wales sexual assault service: An exploratory study. Work and Stress. 1997;11(4):319-28.

24. Kanter J. Compassion fatigue and secondary traumatization: A second look. Clinical Social Work Journal. 2007;35(4):289-93.

25. Canfield. J. Secondary traumatization, burnout, and vicarious traumatization: A review of the literature as it relates to therapists who treat trauma. Smith College Studies in Social Work. 2005;75(2):81-101.

26. Kassam-Adams N. The risk of treating sexual trauma: Stress and secondary trauma in psychotherapists. 1995.

27. Lobel JA. The vicarious effects of treating female rape survivors: The therapist's perspective (Unpublished doctoral dissertation). University of Pennsylvania. 1997.

28. Pearlman LA, McCann PS. Vicarious traumatization: An empirical study of the effects of trauma work on trauma therapists. Professional Psychology: Research and Practice. 1998;26(6):558-65.

29. Arvay MJ. Secondary traumatic stress among trauma counselors: What does the research say? International Journal for Advancement of Counseling. 2001;23(4):283-93. 
www.yumedtext.com | November-2019

30. Pyles L. Postmus JL. Addressing the problem of domestic violence: How far have we come? Affilia. 2004;19(4):376-88.

31. Remer R, Ferguson R. Becoming a secondary survivor of sexual assault. Journal of Counseling \& Development. 1995;73(4):407-13.

32. Sommer CA. Vicarious traumatization, trauma-sensitive supervision, and counselor preparation. Counselor Education and Supervision. 2008;48(1):61-71.

33. Sommer CA, Cox JA. Elements of supervision in sexual violence counselors' narratives: A qualitative analysis. Counselor Education and Supervision. 2005;45(2):119-34.

34. Dworkin E, Sorell N, Allen N. Individual-and setting-level correlates of secondary traumatic stress in rape crisis center staff. J Interpers Violence. 2016;31(4):743-59.

35. Good DA. Secondary traumatic stress in art therapists and related mental health professionals Dissertation Abstracts International Section A: Humanities and Social Sciences.1996;57(6-A): 2370.

36. Rzeszutek M, Partyka M, Andrzej P. Temperament traits, social support, and secondary traumatic stress disorder symptoms in a sample of trauma therapists. Professional Psychology, Research and Practice. 2015;46(4):213-24.

37. Schauben LJ, Frazier P. Vicarious trauma: The effects on female counselors of working with sexual violence survivors. Psychology of Women Quarterly. 1995;19(1):49-64.

38. Breidling MJ, Smith SG, Basile KC, et al. Prevalence and characteristics of sexual violence, stalking, and intimate partner violence victimization. American Journal of Public Health. 2014;63(8):1-18.

39. Warshaw C, Sullivan C, Rivera EA. A systematic review of trauma-focused interventions for domestic violence survivors. National Center on Domestic Violence, Trauma, and Mental Health. 2013.

40. Hensley PH. The value of supervision. The Clinical Supervisor. 2002;21(1):97-110.

41. Bogo M, McKnight K. Clinical supervision in Social Work. The Clinical Supervisor. 2006;24(1-2):49-67.

42. Pulido ML. In their words: Secondary traumatic stress in social workers responding to the $9 / 11$ terrorist attacks in New York City. Social Work. 2007;52(3):279-81.

43. Bride BE, Robinson M M, Yegidis B, et al. Development and Validation of the Secondary Traumatic Stress Scale. Research on Social Work Practice, 2004;14(1):27-35.

44. Kessler R, Chiu WT Demler O, Merikangas KR, et al. The Prevalence, severity, and comorbidity of 12-month DSM-IV disorders in the National Comorbidity Survey Replication. Arch Gen Psychiatry. 2005;62(6):617-27.

45. Bride BE. Prevalence of Secondary Traumatic Stress among Social Workers. Social Work. 2007;52(1):63-70.

46. Kadushin A, Harkness D. Supervision in Social Work. New York: Columbia University Press. 2014.

47. Tsui M. The roots of social work supervision: An historical review. The Clinical Supervisor. 1997;15(2):191-98.

48. Walker M. Supervising practitioners working with survivors of childhood abuse: Counter transference, secondary traumatization and terror. Psychodynamic Practice: Individuals, Groups and Organizations. 2004;10(2):173-93.

49. Stoltenberg CD, MNeill B, Delworth U. IDM supervision: An integrated developmental model for supervising counselors and therapists. San Francisco: Jossey- Bass. 1998.

50. Harrison RL, Westwood MJ. Preventing vicarious traumatization of mental health therapists: Identifying protective practice. Psychotherapy (Chic). 2009;46(2):203-19. 